\title{
УДК [613.6+613.27]:001.5
}

\section{СОАИ КАК ОБЪЕКТ ГИГИЕНИЧЕСКОГО НОРМИРОВАНИЯ В ВОЗАУХЕ РАБОЧЕЙ ЗОНЫ}

\author{
Коршун М. Н.', Краснокутская А. М.2 \\ ' Комитет по вопросам гигиенического регламентирования МЗ Украины, г. Киев \\ 2 ГУ «Институт меАицины трУАа НАМН Украины», г. Киев
}

В статье содержится анализ класса неорганических солей как объекта санитарно-токсикологической оценки и гигиенического нормирования в воздухе рабочей зоне, проведенный под углом зрения учета биологической роли как катиона, так и аниона, и способности их к комплексообразованию. Токсичность веществ в целом снижается в ряду мягкие-амфотерные (промежуточные)-жесткие катионы (кислоты Льюиса), хотя строгого параллелизма нет. Преобладающее влияние катиона в токсичности солей служит основанием их группового гигиенического нормирования. Отмечено особое место амфотерных кислот Льюиса (многие из них - $\mathrm{Fe}^{2+}, \mathrm{Cu}^{2+}$, $\mathrm{Mn}^{2+}, \mathrm{Co}^{2+}, \mathrm{Zn}^{2+}$ - являются микроэлементами), которые легко реагируют с лигандами всех типов.

Ключевые слова: соли, катионы и анионы, комплексообразование, гигиенические нормативы, воздух рабочей зоны

\section{Введение}

Согласно современным представлениям, соли образуют особый класс химических соединений, имеющих ионную структуру. Являясь продуктом взаимодействия кислот и оснований, соли могут рассматриваться и как результат замещения протона водорода кислот ионами металлов и $\mathrm{NH}^{4+}$, и как продукт замещения $\mathrm{OH}^{-}$оснований анионами кислот (кислотными остатками). В зависимости от степени замещения различают средние (результат полного замещения, соли типа $\mathrm{Na}_{2} \mathrm{SO}_{4}$ ), кислые (типа $\mathrm{NaHSO}_{4}$ ) и основные (типа $\mathrm{Fe}(\mathrm{OH}) \mathrm{SO}_{4}$ ) как результат частичного замещения - соли. Кислотные остатки могут принадлежать как минеральным (типа азотной или серной), так и органическим (типа уксусной) кислотам. Во втором случае, несмотря на органический характер кислотного остатка, образованное соединение остается неорганическим, в силу отсутствия связи металлуглерод, как это имеет место в металлорганических соединениях (например, диметилртути или этилмеркурхлориде), в которых углерод органического радикала связан с металлом. Типичные соли - кристаллические вещества, характеризующиеся относительно высокими значениями температур кипения и плавления [1,9].

Соли являются традиционным объектом токсикологического исследования. Показательно, что многие кардинальные вопросы общей токсикологии металлов (в т. ч. и их гигиеническое нормирование) рассмотрены именно на примере солей [5]. Однако, задача настоящей работы состояла не в

том, чтобы изложить вопросы теории и практики гигиенического нормирования вредных веществ на примере солей, а в том, чтобы рассмотреть и оценить класс солей как объект гигиенической (санитарно-токсикологической) оценки [4]. С позиции токсиколого-гигиенической оценки и методологических подходов к гигиеническому нормированию веществ соли представляют собой такую группу соединений, биологическая активность (в том числе и токсичность) которых несет в себе отражение относительно легко определяемого влияния состава и строения молекул. В качестве примера, иллюстрирующего влияние катиона и аниона (молекулы в целом) в реализацию токсического эффекта приведем данные, касающиеся галогенидов сурьмы [6]. Так, в острых опытах была выявлена большая токсичность $\mathrm{SbF}_{3}$ по сравнению с другими соединениями сурьмы, что, по мнению авторов, дает основание связывать ее с наличием фтора в этом соединении. В опытах с длительным введением $\mathrm{SbF}_{3}$ выявлены эффекты, обязанные как влиянию сурьмы, так и влиянию фтора. К числу последних авторы относят гипергликемию и более выраженные изменения в легких, в частности, увеличение легочного коэффициента.

Особенности нормирования. В связи с изложенным представляется логичной попытка сгруппировать всю совокупность солей следующим образом:

- подгруппа солей - производных биологически активных катионов (например, таких элементов, как $\mathrm{Ag}, \mathrm{Be}, \mathrm{Li}, \mathrm{Ni}, \mathrm{Cd}, \mathrm{Pb}, \mathrm{Hg}, \mathrm{Tl}, \mathrm{U}$ и некоторых других) и относительно малоактив- 
ных кислотных остатков (например, $\mathrm{Cl}^{-}, \mathrm{NO}^{3-}$, $\mathrm{CO}_{3}^{2-}, \mathrm{SO}_{4}^{2-}, \mathrm{PO}_{4}^{3-}$ и других);

- подгруппа солей - производных биологически активных анионов (например, $\mathrm{CN}^{-}, \mathrm{F}^{-}$, $\left.\mathrm{Br}^{-}, \mathrm{J}^{-}\right)$;

- подгруппа солей, образованных относительно умеренно- или малоактивными в токсикологическом отношении катионами $\left(\mathrm{NH}^{4+}, \mathrm{Na}^{+}, \mathrm{K}^{+}\right.$, $\mathrm{Mg}^{2+}, \mathrm{Ca}^{2+}$ ) и анионами.

Последующий анализ проведен с использованием представления о «жестких» и «мягких» кислотах и основаниях [7]. Термин «кислота»в данном контексте относится к ионам металла в его формальном состоянии окисления (кислота Льюиса), а основания - к донорным атомам лиганда. О жесткости (мягкости) кислот и оснований принято судить по тому, в какой степени классифицируемые вещества напоминают $\mathrm{Fe}^{3+}$ и $\mathrm{Hg}^{2+}$ в их отношении к галогенидам. Было установлено, что константы устойчивости галогенидных комплексов $\mathrm{Fe}^{3+}$ понижаются в ряду $\mathrm{F}^{-}>\mathrm{Cl}^{-}>\mathrm{Br}^{-}$ $>\mathrm{I}^{-}$; в противоположность этому $\mathrm{Hg}^{2+}$ образует более устойчивые комплексы с более тяжелыми галогенидами и константы устойчивости понижаются в ряду $\mathrm{I}^{-}>\mathrm{Br}^{-}>\mathrm{Cl}^{-}>\mathrm{F}^{-}$. Металлы, которые ведут себя подобно $\mathrm{Fe}^{3+}$, отнесены к классу (а или жестких), а металлы, которые ведут себя подобно $\mathrm{Hg}^{2+}$ - к классу (б или мягких) кислот Льюиса. Существуют металлы, подчиняющиеся некоторым тенденциям класса (а) и некоторым тенденциям класса (б) ионов металлов. В рамках данной классификации они располагаются в пограничной области металлов и могут рассматриваться как промежуточные, или «амфотерные» (от греч. amphoteros- и тот, и другой); аналогичным образом классифицируются лиганды.

Поведение кислот и оснований подчиняется эмпирическому правилу: жесткие ионы металлов предпочитают координировать жесткие лиганды, а мягкие ионы металлов предпочитают координировать мягкие лиганды. Показано также, что биологические комплексы состоят преимущественно из ионов жестких металлов и лигандов. В тканях организма (за некоторым исключением) преобладают донорные атомы жестких лигандов - кислорода и азота, и жесткие щелочные и щелочноземельные металлы. При этом соединения, представляющие яды для живых организмов, часто относятся к классу как мягких лигандов ( $\mathrm{CO}, \mathrm{CN}^{-}$, $\mathrm{H}_{2} \mathrm{~S}$ ), так и мягких кислот, например, $\mathrm{Hg}^{2+}$. Если эти биологически активные компоненты присутствуют в высоких концентрациях, то они взаимодействуют с жесткими ионами металлов и лигандами организмов, препятствуя тем самым их нормальному функционированию.

Металлы, образующие первую подгруппу, за некоторым исключением, напоминают перечень мягких кислот Льюиса, щелочные и щелочноземельные металлы - жесткие кислоты Льюиса.

Представители первой подгруппы, как правило, нормированы по катиону (металлу) и норматив носит групповой характер. Этому способствует то, что и металл, и его соли находятся в воздухе в одном и том же агрегатном состоянии в виде аэрозоля. Исключение составляет ртуть и неорганические ртутьсодержащие соединения (HPC), которые находятся в воздухе соответствен-

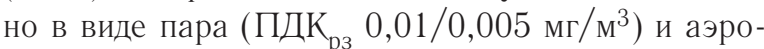
золя (ПДК $\left.\mathrm{K}_{\mathrm{p}} 0,2 / 0,05 \mathrm{мг} / \mathrm{m}^{3}\right)$. Такое различие имеет под собой весомое основание: пары ртути поглощаются в легких на $(80-90) \%$, аэрозоли НРС - (10-15) \% и менее. В целом, токсичность металлов по величине ЛД 50 при всех путях поступления в организм снижается в ряду мягкиеамфотерные-жесткие кислоты Льюиса. В то же время последовательность металлов по смертельному эффекту не всегда соответствует таковой по биологическим эффектам на токсическом уровне, что связано с тем, что жесткие кислоты Льюиса, не вызывая смертельных эффектов, благодаря способности образовывать прочные недиссоциирующие комплексы (преципитаты), являются сильными конкурентами биоэлементам и приводят тем самым к дискоординации обмена веществ [10].

Токсичность, опасность и специфические проявления биологического действия веществ этой подгруппы обусловливает катион. Преобладание эффекта катиона, даже при наличии относительно биологически активного аниона, можно проиллюстрировать на примере галогенидов - бромида и иодида - таллия, ПДК (1 класс опасности), в то время, как бромид и иодид калия нормированы на уровне 3 мг/м ${ }^{3}$ (3 класс опасности). Роль аниона в основном сводится к тому, что он определяет растворимость веществ в воде (их транспортабельность), и тем самым влияет на дозу вещества, поступившую во внутреннюю среду организма. Кроме того, анион оказывает влияние на степень диссо- 
циации вещества, что в свою очередь сказывает ся на взаимодействии катионов с биосубстратами организма и на судьбе образующихся при этом продуктов. В частности, для галоидных соединений металлов и металлоидов большое значение имеет степень ассоциации и гидролиза, в процессе которого образуются кислоты, оказывающие раздражающий эффект.

То, что острая токсичность веществ зависит от их растворимости, не вызывает сомнения. Қак отмечает И. В. Саноцкий [8], токсичность солей таллия (ацетата, нитрата, сульфата, карбоната, фторида, хлорида, бромида, иодида) при введении в желудок снижается по мере уменьшения их растворимости, хотя прямой пропорциональности нет. Қак константа, определяющая транспортабельность, растворимость лимитирует токсичность веществ при воздействии их относительно больших - на уровне смертельных и токсических доз (концентраций). Однако по мере снижения концентрации в воздухе и воде процент всасывания плохо растворимых веществ в желудочнокишечном тракте и в легких по отношению к введенной дозе (уровню экспозиции) повышается. Косвенным подтверждением этого тезиса может служить рост куммулятивности нерастворимых солей ртути по мере снижения (повышение дробности) ежедневно вводимых в организм доз по методу Ю. С. Қагана - В. В. Станкевича при отсутствии такого рода эффекта у растворимых соединений, всасывание которых практически не зависит от вводимой дозы [3]. А поскольку нормативы устанавливаются на уровне более низком, чем пороговый (подпороговом, недействующим с введением коэффициента запаса к порогу хронического действия), растворимость перестает играть роль фактора, влияющего на величину норматива. В выделенной нами первой подгруппе только соединения урана нормированы с учетом

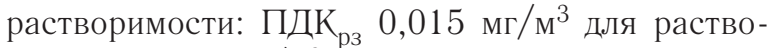
римых и 0,075 мг $/$ м $^{3}$ для нерастворимых соединений, хотя и те и другие отнесены к первому классу опасности. Таким образом, при действии «ускользающе» низких уровней (доз или концентраций) неорганических веществ первой из выделенных выше подгрупп, растворимость практически перестает играть роль фактора, лимитирующего токсичность, а, следовательно, и величину гигиенического норматива. Хотя внутри подгруппы по параметрам токсикометрии имеет место относительно большой разброс данных, достигающий иногда порядка, тем не менее, для них устанавливается единый по катиону норматив и единый первый класс опасности. На фоне доминирования катиона токсические эффекты, которые были бы обязаны анионам, практически не выявляются.

Отмеченные закономерности в меньшей степени присущие, в частности, солям бария, меди, рубидия, серебра и стронция, для которых, наряду с групповыми, существуют и индивидуальные гигиенические нормативы, отражающие значительный вклад конкретных анионов, действующих в составе молекулы на фоне катионов на порядок более низкой активности (табл. 1). Это может служить аргументом к выделению подгруппы биологически активных веществ, соответствующих амфотерным кислотам Льюиса. Ионы амфотерных кислот это, как правило, двузарядные ионы переходных металлов - микроэлементов $\mathrm{Fe}^{2+}, \mathrm{Co}^{2+}, \mathrm{Ni}^{2+}$, $\mathrm{Cu}^{2+}, \mathrm{Zn}^{2+}, \mathrm{Pb}^{2+}$ и некоторых других - отличаются выраженным сродством к лигандам всех трех классов при трудной предсказуемости устойчивости образующихся комплексных соединений. Именно поэтому, на основе амфотерных кислот Льюиса

Гигиенические нормативы некоторых металлов и их солей в воздухе рабочей зоны,

Таблища 1 (мг $/ \mathrm{м}^{3} ;$ класс опасности)

\begin{tabular}{|c|c|c|c|c|c|}
\hline \multirow{2}{*}{ Анионы } & \multicolumn{5}{|c|}{ Катионы } \\
\cline { 2 - 6 } & $\mathbf{A g}^{+}$ & $\mathbf{R b}^{+}$ & $\mathbf{B a}^{\mathbf{2}^{+}}$ & $\mathbf{C u}^{\mathbf{2 +}}$ & $\mathbf{S r}^{\mathbf{2 +}}$ \\
\hline $\mathrm{Cl}^{-}$ & 0,$5 ; 3$ & 0,$5 ; 3$ & 0,$3 ; 2$ & 0,$5 ; 2$ & - \\
\hline $\mathrm{NO}_{3}{ }^{-}$ & 0,$5 ; 2$ & 0,$5 ; 2$ & $1,5 / 0,5 ; 2$ & - & 1,$0 ; 2$ \\
\hline $\mathrm{CO}_{3}{ }^{2-}$ & 0,$5 ; 2$ & 0,$5 ; 2$ & $1,5 / 0,5 ; 2$ & - & 6,$0 ; 4$ \\
\hline $\mathrm{SO}_{4}{ }^{2-}$ & - & 0,$5 ; 2$ & 6,$0 ; 4$ & 0,$5 ; 2$ & 6,$0 ; 4$ \\
\hline $\mathrm{PO}_{4}{ }^{3-}$ & - & - & 0,$5 ; 2$ & 2,$0 ; 3$ & 6,$0 ; 4$ \\
\hline
\end{tabular}

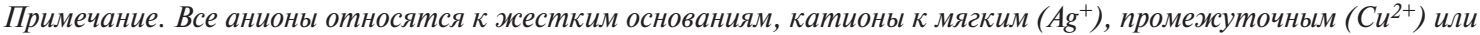
неидентифицированным ( $\left.\mathrm{Rb}^{+}, \mathrm{Ba}^{2+}, \mathrm{Sr}^{2+}\right)$ кислотам в рамках классификации по Г. Эйхгорну [7]. 
возможны групповые нормативы, но при этом должны быть определены вещества, свойства которых требуют индивидуального подхода к нормированию. В их числе сульфиды, карбонаты, сульфат бария и другие. Если гигиенические нормативы солей первой из выделенных нами подгрупп находятся на уровне сотых долей мг/м³ этой промежуточной подгруппы, как правило, находятся на уровне десятых долей мг/ $\mathrm{m}^{3}$, что соответствует 2-му классу опасности - высокоопасные вещества по ГОСТ 12.1.007-76.

Вторая подгруппа малочисленна и полярна по отношению к первой подгруппе веществ. Наиболее представительными являются фториды, внутри которых выделены растворимые и нерастворимые производные, нормативы которых (соответственно $1,0 / 0,2$ и 2,5/0,5 мг/м ${ }^{3}$ ) отличаются в 2,5 раза. При этом норматив водорода фторида $(0,5 / 0,1$ мг $/ \mathrm{m}^{3}$ ) ниже, чем нормативы водорастворимых солей. В отличие от этого, норматив гидроциана $\left(0,3\right.$ мг $\left./ \mathrm{M}^{3}\right)$ численно равен нормативу соответствующих солей $\left(0,3\right.$ мг $/ \mathrm{m}^{3}$ в пересчете на гидроциан). Бромиды и иодиды в острых опытах не проявляют «высокой токсичности», так как доминирует влияние катиона. Но в хроническом эксперименте при воздействии малых доз проявляют «специфические» эффекты, обязанные аниону. Как следствие, ПДКрз иодида и бромида калия $\left(3 \mathrm{мг} / \mathrm{M}^{3}\right)$ почти в 2 раза ниже, чем ПДК его хлорида $\left(5\right.$ мг $\left./ \mathrm{m}^{3}\right)$. Арсениды - производные мышья ковистого водорода (арсина) и фосфиды - производные фосфористого водорода (фосфина) - не нормированы. Однако, на практике сталкиваемся с некоторыми противоречиями. Так, наряду с нормативом серебра неорганических соединений $\left(0,5\right.$ мг $\left./ \mathrm{m}^{3}\right)$ действует ПДК рз фторида серебра и, как ни странно, на более высоком уровне $1,0 / 0,2$ мг $/ \mathrm{m}^{3}$. Фторид лития нормирован как

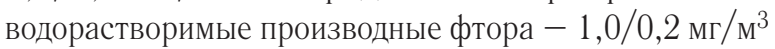
по фтору; в то же время в Российском законодательстве существует норматив лития и его растворимых неорганических соединений $-0,02$ мг/м ${ }^{3}$ по литию, аэрозоль, 1-й класс опасности. При этом, норматив в отношении нерастворимых соединений отсутствует. В целом, бромиды, иодистые и фтористые соли металлов невысокой токсичности оказывают биологическое (часто специфическое) действие именно своими анионами. Это хорошо известно и используется в клинической практике: успокаивающий эффект бромидов, регулирующийся иодидами уровень функциональной активности щитовидной железы, и в экспери менте - специфическими эффектами на процессы гликолиза и строение костной ткани со стороны фторидов. Данные о большей токсичности иодидов и бромидов металлов в сравнении с хлоридами приведены Э. Н. Левиной [5]. Тем не менее, групповые нормативы, основанные на общем анионе, возможны для ограниченного числа веществ производных малоактивных катионов.

Наиболее многочисленной и «пестрой» является третья подгруппа солей, информация о значениях ПДК таблице 1. Обращает на себя внимание то, что значения ПДК $\mathrm{pз}_{\text {з }}$ колеблются в широком диапазоне, а вещества, за редким исключением (нитрат кальция), относятся к 3-4 классам опасности. Из приведенных данных следует, что вклад катионов в токсикометрические показатели веществ этой подгруппы соизмерим с вкладом анионов, роль которых не ограничивается их влиянием на растворимость веществ в воде. Природа аниона влияет на условия высвобождения ионов (разрыв связей металл-анион) и последующее взаимодействие катиона с субстратами организмов.

Приведенные в таблице 1 данные не позволяют говорить о преобладающем эффекте действия катиона или аниона. Именно для веществ третьей подгруппы биологический эффект есть результатом действия молекулы в целом, именно для этих веществ необходим, пусть кратковременный, токсиколого-гигиенический эксперимент, так как прогнозировать значение гигиенического норматива (ГН) затруднительно. Именно соли угольной кислоты, сульфаты или сульфиды биологически относительно умеренно активных катионов могут быть веществами, для которых нормирование по групповому принципу может оказаться невозможным, так как указанные вещества в силу трудно прогнозируемых эффектов совместного действия как анионов, так и катионов могут «выйти за пределы» того диапазона значений параметров токсикометрии и/или значений ПДК установление группового норматива. Ранее [2] нами, на примере фторидов хрома и меди, было обращено внимание на то, что соблюдение ГН по аниону не всегда гарантирует допустимую экспо зицию катиона. В любом случае, нормируя соли, содержащие относительно активные катионы и 
Таблица 2

Гигиенические нормативы некоторых солей, содержащих относительно малои умеренно-активные в токсикологическом отношении катионы и анионы

\begin{tabular}{|c|c|c|c|c|c|}
\hline \multirow{3}{*}{ Катионы } & \multicolumn{5}{|c|}{ Анионы } \\
\hline & \multicolumn{5}{|c|}{ Значение ПДК } \\
\hline & $\mathrm{Cl}^{-}$ & $\mathrm{NO}_{3}^{-}$ & $\mathrm{CO}_{3}{ }^{2-}$ & $\mathrm{SO}_{4}{ }^{2-}$ & $\mathrm{PO}_{4}{ }^{3-}$ \\
\hline $\mathrm{NH}_{4}^{+}$ & 10,$0 ; 3$ & 5,$0 ; 3$ & - & 10,$0 ; 3$ & 10,$0 ; 4^{*}$ \\
\hline $\mathrm{Na}^{+}$ & 5,$0 ; 3$ & 5,$0 ; 3$ & 2,$0 ; 3$ & 10,$0 ; 3$ & 10,$0 ; 4$ \\
\hline $\mathrm{K}^{+}$ & 5,$0 ; 3$ & 5,$0 ; 3$ & 2,$0 ; 3$ & 10,$0 ; 3$ & 10,$0 ; 4$ \\
\hline $\mathrm{Mg}^{2+}$ & 5,$0 ; 3$ & - & 10,$0 ; 4^{*}$ & 2,$0 ; 3$ & 10,$0 ; 4^{*}$ \\
\hline $\mathrm{Ca}^{2+}$ & 2,$0 ; 3$ & 2,$5 ; 2$ & - & 2,$0 ; 3^{*}$ & 10,$0 ; 4$ \\
\hline
\end{tabular}

Примечание. Все катионы, за исключением $\mathrm{NH}^{4+}$, и все анионы относятся соответственно к классу жестких оснований и кислот; * приведено значение норматива, установленного в РФ.

анионы, следует устанавливать нормативы таким образом, чтобы «экспозиционная концентрация» соответствовала ПДК аргументируется целесообразность установления индивидуальных, а не групповых, нормативов для веществ данной подгруппы. Последние в наибольшей степени несут на себе отпечаток действия молекулы в целом. Их значения (табл. 2) колеблются в диапазоне $(2-10)$ мг $/ \mathrm{m}^{3}$, но чаще всего $(5-10)$ мг $/ \mathrm{M}^{3}$. Так, на уровнях $(5-10)$ мг $/ \mathrm{M}^{3}$ нормированы натриевые, калиевые, магниевые соли азотной, серной, фосфорной и соляной кислот и, в отдельных случаях, производные угольной кислоты.

Величина 10 мг/м³ выступает как своеобразный групповой гигиенический норматив аэрозолей веществ, молекулы которых состоят из относительно биологически инертных анионов и катионов. Можно признать корректным и попытки прогнозирования их токсичности, опасности и значения ПДК (ОБУВ)рз на основании аналогии с сопоставимыми по катионам и анионам веществами.

Однако, далеко не всегда величина 10 мг/ $\mathrm{m}^{3}$, как допустимое содержание аэрозолей веществ в воздухе рабочей зоны, отражает его химикотоксикологическую безопасность. При одном и том же значении ПДК равной $10 \mathrm{мг} / \mathrm{M}^{3}$, они в одном случае признаны веществами 3-го, а в другом 4-го классов опасности. Отнесение веществ с ПДК 10 мг $/$ м $^{3}$ к соединениям 3-го класса опасности по ГОСТ 12.1.007 однозначно свидетельствует, что класс опасности установлен с учетом токсикометрических показателей, чего нельзя сказать о веществах 4-го класса опасности. К ним естественно отнесены вещества, все (и это очень важно) параметры токсико- метрии которых соответствуют 4-му классу опасности (если хотя бы один параметр, приведенный в ГОСТ 12.1.007, соответствовал бы значениям 3 -го, а тем более 2 -го или 1 -го классов опасности, то согласно п.1.3. цитируемого ГОСТ вещество должно быть отнесено к 3 -му, 2 -му и 1 -му классам опасности соответственно). Среди соединений 4 -го класса опасности многие нормативы находят ся на уровне, значительно превышающем 10 мг/ м $^{3}$. В качестве крайних приведем значение ПДК этилового спирта - 1000 мг $/$ м $^{3}$, что в 100 раз превышает приведенный норматив, или фреонов с ПДК встречаются только среди веществ, находящихся в воздухе в паровой фазе. Для аэрозолей значение

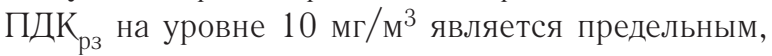
но не в силу их токсического действия. Величина ПДК 10 мг/ м $^{3}$ защищает работающего в конкретном случае не столько от химико-токсического действия пыли, сколько от физико-механического эффекта воздействия биологически инертной пылью. Если исходить исключительно из токсикологических соображений, то ПДК более высоком уровне, что, однако, недопустимо.

Сопоставляя значения ПДК подгруппы (находится на уровне сотых долей мг $/ \mathrm{m}^{3}$ ), из сформированных нами, со значением ПДК веществ третьей подгруппы (находятся на уровне величин в диапазоне от 2 до 10 мг/ м $^{3}$ ), легко убедиться, что при соблюдении ПДК ${ }_{\text {з }}$ в первом случае в организм поступит примерно на 2 порядка меньше анионов, чем это имело бы место применительно к веществам третьей подгруппы. Таким образом, собственной токсичностью анионов при оценке веществ первой подгруппы, 
можно пренебречь. Применительно к веществам третьей группы эффект аниона не ограничивает ся влиянием на растворимость веществ (транспортабельность катиона). В частности, при внутрибрюшинном введении галогенпроизводных ртути (II) влияние растворимости нивелируется возможным снижением энергии разрыва связи металл-галоген в ряду хлор-бром-йод в результате соответствующего увеличения расстояния между ними с 2,25 до 2,75 нм. Более подробно вопрос роли аниона в токсическом действии солей (на примере ртутьсодержащих соединений ) рассмотрен в специальной публикации [3].

\section{Выводы}

Отнесение вещества к тому или иному классу кислот или оснований облегчает решение задачи их гигиенического регламентирования. Применительно к металлам нормирование веществ, относящихся к мягким и промежуточным кислотам, должно изначально строиться таким образом, чтобы:

а) определить оправданность (обоснованность) установления для них (или какой-то их части) группового норматива;

б) обосновать такого рода групповой норматив, который бы удовлетворял требованиям надежности для наиболее токсичных (опасных) представителей этой подгруппы.

\section{Литература}

1. Загальна хімія: підручник; за ред. О. А. Голуба.К.: Вища школа, 2006.- 471 с.

2. Коршун М. Н. К теории и практике группового регламентирования вредных веществ в воздухе рабочей зоны (на примере неорганических соединений) / М. Н. Коршун / / Совр. пробл. токсикол.- 2006.- № 3.C.77-81.

3. Коршун М. Н. Роль аниона в токсическом действии неорганических ртутьсодержащих веществ / М. Н. Коршун // Фармакол. и токсикол.- К.: Здоров'я, 1998.- Вып. 23.- С. 106-110.

4. Коршун М. Н. Современные тенденции гигиенического нормирования вредных веществ в воздухе рабочей зоны (обзор литературы) / М. Н. Коршун // Укр. журн. з пробл. мед. праці.- 2006.№ 3 (7).- C.71-76.
При выборе химических элементов, которые могли бы послужить ядром группового регламентирования, можно опираться на параметры токсикометрии хлорпроизводных указанных элементов. Если по величине ЛД 50 per os для крыс (мышей) вещество соответствует 1-2 классам опасности по ГОСТ 12.1.007 и отличается выраженной кумуляцией (коэффициент кумуляции по Кагану-Станкевичу до 3), то вероятность того, что нормирование солей, основанных на данном элементе, будет при соблюдении особых требований и условий осуществлено по групповому принципу, высокая.

При нормировании веществ, относящихся к жестким кислотам, необходимо исходить из принципа приоритетности установления индивидуального значения ПДК рз отдельных веществ, и только после нормирования на индивидуальной основе ряда представителей подгруппы можно решать вопрос о целесообразности установления группового норматива. При этом, для веществ этой подгруппы обязательным является наличие экспериментального фрагмента обоснования норматива, объем, и содержание которого зависят от целого ряда условий. K числу условий, которые могут служить основанием для сокращения объема экспериментальных исследований, относится наличие утвержденных нормативов родственных в химическом отношении веществ.

5. Левина Э. М. Общая токсикология металлов / Э. М. Левина.- М.: Медицина, Ленинградское отд., 1972.- $184 \mathrm{c}$.

6. Левина Э. М. О токсичности некоторых галогенидов Сурьмы / Э. М. Левина, М. П. Чекунова // Гиг. тр. и проф. заболев.- 1964.- № 7.- С.25-31.

7. Неорганическая биохимия: под ред. Г. Эйхгорна; пер.с англ.- М., «Мир", 1978.- Т.1.- 712 с.

8. Саноцкий И. В. Исследование токсичности соединений таллия (карбоната, иодида и бромида таллия) / И. В. Саноцкий // Токсикол. нов. пром. веществ.- М.: Медицина, 1961, - Вып. 2.- С. 94-104.

9. Химическая энциклопедия.- М.: НИ "Большая Российская энциклопедия", 1995.- Т. 4.- С. 744-746.

10. Чекунова М. П. Современные представления о биологическом действии металлов / М. П. Чекунова, А. Д. Фролова // Гиг. и сан.- 1986.- № 12.- С.18-21. 


\section{Коршун М. М.', Краснокутсыка А. М.²

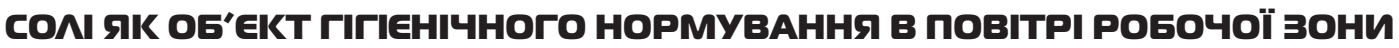

' Комітет з питань гігієнічного регламентування МОЗ України, м. Київ

$\Delta$ У « Інститут меАицини праші НАМН України», М. Київ

Стаття містить аналіз класу неорганічних солей як предмет санітарно-токсикологічної оцінки та гігієнічного нормування в повітрі робочої зони, що проведений під кутом зору урахування біологічної ролі як катіона, так і аніона, і здатності їх до комплексоутворення. Токсичність речовин в цілому зменшується в ряду м'які-амфотерні (проміжні)-жорсткі катіони (кислоти Льюїса), але суворого паралелізму немає. Переважний вплив катіонів у токсичності солей слугує підставою їхнього групового гігієнічного регламентування. Зазначено особливе місце амфотерних кислот Льюїса (багато з їх числа - $\mathrm{Fe}^{2+}, \mathrm{Cu}^{2+}, \mathrm{Mn}^{2+}, \mathrm{Co}^{2+}, \mathrm{Zn}^{2+}-\epsilon$ мікроелементами), які легко реагують з лігандами усіх типів.

Ключові слова: солі, катіони та аніони, комплексоутворення, гігієнічні нормативи, повітря робочої зони

\section{Korshun M. M.', Krasnokutskaya L. M.2}

\section{SALTS AS A SUBJECT OF HYGIENIC RATING FOR THE WORIKING ZONE AIR}

${ }^{1}$ Hygienic regulation Committee Ministry of Public Health of Ukraine, Kiev

2 SI «Institute for Occupational Health of NAMS of Ukraine», Kiev

An analysis of the class of inorganic salts as a subject of sanitary and toxicological assessment and hygienic rating for the working zone air is presented in the paper, conducted with due account of the biological part of both cation and anion and their ability to make complexes. The toxicity of a substance in general is decreased in the raw of soft-amphoteric (intermediate)hard cations (Lewis acids), though, there is no strict parallelism. The prevailing effect of the cation in salt toxicity can be used as a basis for hygienic rating of this group. A particular place of amphoteric Lewis acids (many of them $-\mathrm{Fe}^{2+}, \mathrm{Cu}^{2+}, \mathrm{Mn}^{2+}$, $\mathrm{Co}^{2+}, \mathrm{Zn}^{2+}$ are microelements), which easily react with ligands of all types.

Key words: salts, cations and anions, complexes, hygienic standards, working zone air

Поступила: 20.09.2010 2.

Контактное лицо: Коршун М. Н., Комитет по вопросам гигиенического регламентирования МЗ Украины, д.75, ул. Саксаганского, г. Киев, 03033. Тел.: (44) 284-34-27. 